\title{
Produtividade da Brachiaria brizantha cv. Xaraés em diferentes manejos e doses de adubação, períodos de descanso e épocas do ano ${ }^{1}$
}

\author{
Yield of Brachiaria brizantha $c v$. Xaraes in different management \\ and levels of fertilization, rest periods and seasons
Fernando França da Cunha², Márcio Mota Ramos ${ }^{2}$, Carlos Augusto Brasileiro de Alencar ${ }^{2}$, Rubens Alves de Oliveira ${ }^{2}$, Antônio Carlos Cóser ${ }^{3}$, Carlos Eugênio Martins ${ }^{3}$, Paulo Roberto Cecon ${ }^{2}$, Rodrigo Antônio Silva Araújo ${ }^{2}$

\begin{abstract}
RESUMO
Experimentos já foram conduzidos no Leste do Estado de Minas Gerais visando à avaliação de gramíneas forrageiras onde destacou-se a Brachiaria brizantha cv. Xaraés. Diante disso, decidiu-se intensificar a pesquisa conduzindo-se um experimento em esquema de parcelas sub-subdivididas, tendo nas parcelas um esquema fatorial 2 × 2 (épocas climáticas e manejos de adubação), nas subparcelas quatro períodos de descanso e nas sub-subparcelas seis níveis de adubação, no delineamento inteiramente casualizado, com quatro repetições. As épocas climáticas foram outono/inverno e primavera/verão. Os períodos de descanso foram de 21, 28,35 e 42 dias. Os manejos de adubação foram convencional e fertirrigação. Para diferenciar as doses de adubação no tratamento fertirrigado, utilizou-se a aspersão em linha. As doses de adubação tiveram uma relação entre nitrogênio e potássio de $1 \mathrm{~N}: 0,8 \mathrm{~K}_{2} \mathrm{O}$ e foram de $0,15,39,64,83$ e $100 \%$ da referência $\left(700\right.$ e $560 \mathrm{~kg}$ de $\left.\mathrm{N} \mathrm{e} \mathrm{K}_{2} \mathrm{O}\right)$. A produtividade de matéria seca foi obtida por meio do material seco em estufa ventilada a $60{ }^{\circ} \mathrm{C}$, por $72 \mathrm{~h}$. Verificou-se, em geral, que a estação seca apresentou menor produtividade de MS; porém, em média, a produtividade obtida na estação outono/inverno foi de $75 \%$ daquela obtida na estação primavera/verão. Os manejos de adubação não influenciaram os valores de produtividade de MS, porém o aumento da dose de adubação proporcionou efeito linear positivo no capim-xaraés fertirrigado na estação outono/inverno e quadrático nos demais tratamentos. Os períodos de descanso proporcionaram efeito quadrático apenas no tratamento fertirrigado e estação outono/inverno.
\end{abstract}

Palavras-chaves: fertirrigação, aspersão em linha, matéria seca.

\begin{abstract}
In experiments conducted in the eastern part of Minas Gerais in Brazil to evaluate forage grasses, Brachiaria brizantha cv. Xaraes proved to be exceptional. Thus it was decided intensify the research on this grass, conducting a sub-split plot experiment, with plots in a $2 \times 2$ factorial design (seasons and management of fertilization), four rest periods in the subplots and six levels of fertilization in the sub-subplots, in a completely randomized design with four replicates. The seasons were fall/winter and spring/summer. The rest periods were 21,28, 35 and 42 days. The management consisted of application of nitrogen and potassium fertilizers by conventional fertigation. A line-source irrigation system was used apply the fertigation treatments. The fertilization doses had a nitrogen: potassium ratio of $1 \mathrm{~N}: 0.8 \mathrm{~K}_{2} \mathrm{O}$ and were $0,15,39,64,83$ and $100 \%$ of the reference values (700 and $560 \mathrm{~kg}$ of $\mathrm{N}$ and $\mathrm{K}_{2} \mathrm{O}$, respectively). Dry matter yield was obtained after drying material in ventilated stoves at $60^{\circ} \mathrm{C}$ for $72 \mathrm{~h}$. The dry season in general had lower yield of dry matter; the overall yield in the autumn/winter was $75 \%$ of that obtained in the spring/summer. The management of fertilization did not influence the values of dry matter yield, but increasing the dose of fertilization had a positive linear effect on xaraes-grass fertigated in the autumn/winter and a quadratic effect in the other treatments. The rest periods produced a quadratic effect only in the treatments fertigated in the fall/winter season.
\end{abstract}

Key words: fertigation, line source sprinkler system, dry matter.

1 Parte da tese de doutorado do primeiro autor, apresentada ao curso de pós-graduação em Engenharia Agrícola, Departamento de Engenharia Agrícola, Universidade Federal de Viçosa. Avenida Peter Henry Rolfs, s/n. CEP: 36570-000, Viçosa, MG, Brasil

2 Departamento de Engenharia Agrícola, Universidade Federal de Viçosa. Avenida Peter Henry Rolfs, s/n. CEP: 36570-000, Viçosa, MG, Brasil. E-mail: fernando.cunha@ufv.br (Autor para correspondência),mmramos@ufv.br, c.brasileiro@yahoo. com.br, rubens@ufv.br e rodrigoaraujoagro@hotmail.com

3 Centro Nacional de Pesquisa Gado de Leite, Empresa Brasileira de Pesquisa Agropecuária. Rua Eugênio do Nascimento, 610. CEP: 36038-330, Juiz de Fora, MG, Brasil. E-mail: acoser@cnpgl.embrapa.br e caeuma@ cnpgl.embrapa.br

Fecha de Recepción: 22 Julio, 2009.

Fecha de Aceptación: 22 Abril, 2011. 


\section{Introdução}

O Brasil detém o maior rebanho comercial de bovinos do mundo, com cerca de 160 milhões de cabeças. Segundo dados do IBGE (2009), no ano de 2008, a produção de leite ficou em torno de 19,238 bilhões de litros e foram abatidos cerca de 28,691 milhões de cabeças. Diante disso, existe uma grande preocupação atual e futura para que os sistemas de pastejo nesse País se tornem intensificados. Para que isto ocorra, os pecuaristas deverão ser orientados a utilizar sistemas de produção que combinem o uso de tecnologias adequadas, como irrigação e adubação, com forrageiras de maior potencial produtivo. Dessa forma, é possível aumentar o rebanho e, consequentemente, a taxa de lotação animal.

Dentre as forrageiras que têm apresentado sucesso no País, destaca-se a Brachiaria brizantha cv. Xaraés. Em experimento conduzido por Alencar (2007), o capim-xaraés apresentou a maior produtividade em relação a outras forrageiras tradicionalmente plantadas no Brasil.

É fato também que a irregularidade do regime pluvial torna-se restritiva ao desenvolvimento agrícola, pois, mesmo dentro de estações chuvosas, observam-se períodos de déficit hídrico acentuados. A evapotranspiração da pastagem geralmente excede à precipitação pluvial, sendo a irrigação uma garantia para se produzir como planejado, evitando que a falta de chuvas altere os índices de produtividade e de rentabilidade previamente estabelecidos (Cunha et al., 2007).

Os benefícios da irrigação são potencializados quando associados à adubação (Andrade et al., 2000). Em pastagens irrigadas, existe a possibilidade de aplicar fertilizantes juntamente com a água de irrigação. Ter um sistema de irrigação e não aproveitar a fertirrigação é um contra-senso, visto que ela proporciona diversas vantagens à forma convencional de aplicação de certos fertilizantes.

Recentemente, as pesquisas com irrigação de pastagens apresentaram resultados pouco animadores, gerando uma crença de que a irrigação de pastagens durante o período seco do ano não era uma técnica viável. No passado isto era verdadeiro, pois a pecuária mais desenvolvida do País estava concentrada, em grande parte, em regiões onde predominam temperaturas de inverno que não permitem que as forrageiras tropicais se desenvolvam em seu potencial. No entanto, na região Leste do Estado de Minas Gerais, que possui baixas latitude e altitude, e consequentemente maiores temperaturas mínimas de inverno, a situação muda e essa generalização não é mais válida. Além do mais, boa parte das cultivares do passado já não são mais exploradas comercialmente e as técnicas empregadas, como adubação, também já não são mais as mesmas.

A literatura existente sobre o desempenho agronômico e econômico de pastagens irrigadas na região Leste do Estado de Minas Gerais ainda é escassa. O uso da adubação e da irrigação em pastagens ainda é fundamentado em experiências empíricas de produtores, desprovidos de referências de resultados de pesquisas científicas. Portanto, há necessidade de se determinar o desempenho de cultivares de forrageiras irrigadas, que apresentem adequadas características agronômicas e de consumo pelos animais, tais como os apresentados pela Brachiaria brizantha cv. Xaraés. Do exposto, objetivou-se, com este trabalho, avaliar os efeitos de diferentes manejos e doses de adubação, períodos de descanso e épocas climáticas sobre a produtividade de matéria seca do capim-xaraés.

\section{Material e Métodos}

Este trabalho foi conduzido de novembro de 2006 a maio de 2008 e realizado na Universidade Vale do Rio Doce, localizado no município de Governador Valadares, MG, sendo as coordenadas geográficas $18^{\circ} 47^{\prime} 30^{\prime \prime}$ de latitude sul e $41^{\circ} 59^{\prime}$ 04 "de longitude oeste e altitude de $223 \mathrm{~m}$.

O solo na área experimental foi classificado como Cambissolo eutrófico, textura média, com a seguinte composição química na camada de 0 a 40 $\mathrm{cm}: \mathrm{pH}\left(\mathrm{H}_{2} \mathrm{O}\right)=6,3 ; \mathrm{M} . \mathrm{O} .=2,2 \mathrm{~g} \mathrm{dm}^{-3} ; \mathrm{P}=9,1 \mathrm{mg}$ $\mathrm{dm}^{-3} ; \mathrm{K}^{+}=179,5 \mathrm{mg} \mathrm{dm}^{-3} ; \mathrm{Ca}^{+2}=3,1 \mathrm{cmol}_{\mathrm{c}} \mathrm{dm}^{-3}$; $\mathrm{Mg}^{+2}=0,9 \mathrm{cmol}_{\mathrm{c}} \mathrm{dm}^{-3} ; \mathrm{Al}^{+3}=0,1 \mathrm{cmol}_{\mathrm{c}} \mathrm{dm}^{-3}$; $\mathrm{H}+\mathrm{Al}=1,8 \mathrm{cmol}_{\mathrm{c}} \mathrm{dm}^{-3} \mathrm{e} \mathrm{V}=71 \%$. As correções da acidez e fertilidade foram de acordo com as recomendações da CFSEMG (1999).

A distribuição granulométrica e os resultados das análises físico-hídricas do solo foram os seguintes: argila $=30 \%$; silte $=25 \%$; areia $=45 \%$; capacidade de campo $=29 \%$ b.s.; ponto de murcha $=13 \%$ b.s. e densidade do solo $=1,38 \mathrm{~g} \mathrm{~cm}^{-3}$. A densidade do solo foi determinada pelo método do anel volumétrico e os níveis de umidade do solo na capacidade de campo e no ponto de murcha permanente foram determinados para as tensões de 10 e $1.500 \mathrm{kPa}$, respectivamente. Os valores de retenção de água no 
solo foram determinados utilizando-se o método da Câmara de Richards (Richards, 1949).

$\mathrm{O}$ experimento foi conduzido em esquema de parcelas sub-subdivididas, tendo nas parcelas um esquema fatorial 2 × 2 (épocas climáticas e manejos da adubação), nas subparcelas, quatro períodos de descanso e nas sub-subparcelas, seis doses de adubação nitrogenada e potássica, no delineamento inteiramente casualizado com quatro repetições.

As épocas climáticas foram divididas em período seco (outono/inverno) e período chuvoso (primavera/verão). Os períodos considerados para estação outono/inverno foram de 26/04/2007 à $21 / 09 / 2007$ e de 20/03/2008 à 15/05/2008. O período considerado para a estação primavera/verão foi de 22/09/2007 à 19/03/2008. Os períodos de descanso, ou seja, o intervalo entre um pastejo e outro foram de 21, 28, 35 e 42 dias. Os manejos de adubação consistiram em aplicar a adubação nitrogenada e potássica a lanço (convencional) e por meio da água de irrigação (fertirrigação). No manejo de adubação convencional, a aplicação do adubo era realizada após cada pastejo, de tal maneira que os parcelamentos da adubação nos tratamentos de $21,28,35$ e 42 dias foram de 18 , 13, 11 e 9 aplicações, respectivamente. No manejo de adubação fertirrigado, a aplicação do adubo era realizada a cada evento de irrigação, totalizando 22 aplicações. As doses de adubação (DA) foram de $0 \%$ (0 kg de $\mathrm{N}$ e $0 \mathrm{~kg}$ de $\mathrm{K}_{2} \mathrm{O}$ ), $15 \%$ (108 kg de $\mathrm{N}$ e $86 \mathrm{~kg}$ de $\left.\mathrm{K}_{2} \mathrm{O}\right), 39 \%$ (272 $\mathrm{kg}$ de $\mathrm{N}$ e $217 \mathrm{~kg}$ de $\mathrm{K}_{2} \mathrm{O}$ ), 64\% (451 kg de $\mathrm{N}$ e $361 \mathrm{~kg}$ de $\mathrm{K}_{2} \mathrm{O}$ ), $83 \%$ $\left(587 \mathrm{~kg}\right.$ de $\mathrm{Ne} 467 \mathrm{~kg}$ de $\left.\mathrm{K}_{2} \mathrm{O}\right)$ e $100 \%(700 \mathrm{~kg}$ de $\mathrm{N}$ e $560 \mathrm{~kg}$ de $\mathrm{K}_{2} \mathrm{O}$ ).

A dimensão de cada sub-subparcela experimental foi de $3 \mathrm{~m}$ de largura e $3 \mathrm{~m}$ de comprimento, com área de $9 \mathrm{~m}^{2}$. Para diferenciar as doses de adubação no tratamento fertirrigado, utilizou-se a aspersão em linha (Hanks et al., 1976), em que uma linha de aspersores aplicava água juntamente com o adubo e a outra linha fazia apenas a sobreposição com água. O manejo da irrigação foi realizado por meio do monitoramento do potencial de água no solo feita por tensiômetro digital instalado a 15 e $45 \mathrm{~cm}$ de profundidade. As irrigações foram efetuadas quando os tensiômetros instalados a 15 $\mathrm{cm}$ registraram valores de potencial matricial em torno de $-60 \mathrm{kPa}$. A lâmina de irrigação aplicada foi medida com pluviômetros instalados em cada subparcela experimental e calculada por meio da equação 1 .

$$
\mathrm{L}=\frac{(\mathrm{CC}-\theta)}{10} \mathrm{D} \mathrm{Z} \frac{1}{\mathrm{Ea}}
$$

em que: $\mathrm{L}=$ lâmina total necessária $(\mathrm{mm}) ; \mathrm{CC}=$ capacidade de campo (\%,b.s.); $\theta=$ teor atual de água no solo, no potencial matricial de $-60 \mathrm{kPa}(\%$, b.s.); $\mathrm{D}=$ densidade do solo $\left(\mathrm{g} \mathrm{cm}^{-3}\right) ; \mathrm{Z}=$ profundidade efetiva do sistema radicular $(\mathrm{cm})$; e Ea = eficiência de aplicação de água (decimal).

Simultaneamente ao monitoramento da umidade do solo via tensiometria, foram coletados dados meteorológicos diários a partir de uma estação meteorológica automática, instalada dentro da área experimental.

O plantio do capim-xaraés foi realizado em 06/11/2006, utilizando-se sementes com valor cultural de $30 \%$. A semeadura foi realizada manualmente em fileiras espaçadas $30 \mathrm{~cm}$, com sementes distribuídas na profundidade média de $2 \mathrm{~cm}$. O corte de uniformização foi realizado em 27/02/2007 à uma altura de $20 \mathrm{~cm}$ da superfície do solo, realizado de forma mecanizada, utilizando-se um trator equipado com roçadeira. No dia 26/04/2007 realizou-se o pastejo de uniformização, de maneira que o resíduo remanescente pós-pastejo apresentasse em torno de $15 \%$ de folhas verdes remanescentes, conforme recomendação da Embrapa Gado de Leite (Aroeira et al., 1999). O mesmo procedimento foi adotado nas demais coletas e nos pastejos seguintes, porém respeitando o período de descanso de cada tratamento até o término do experimento. Os animais foram utilizados apenas como "ferramenta de corte" após a amostragem de cada gramínea, de maneira que a forragem disponível fosse consumida.

A obtenção da produtividade de matéria seca (MS) foi feita de forma manual, em uma área delimitada por uma unidade amostral metálica, de forma retangular e com o tamanho de $1,0 \times 0,5$ $\mathrm{m}$ (área útil de $0,5 \mathrm{~m}^{2}$ ). A unidade amostral foi posicionada em locais predeterminados, evitando-se coletar amostras sucessivas nas mesmas áreas. Toda a massa verde colhida foi acondicionada em sacos plásticos, devidamente identificados, e imediatamente pesada. Em seguida foi retirada uma subamostra, novamente pesada, acondicionada em saco de papel identificado, e colocada para secar em estufa com circulação de ar a $60{ }^{\circ} \mathrm{C}$, por um período de 72 horas. Após secagem, as subamostras foram pesadas novamente para obtenção do teor de matéria seca (TMS) e produtividade de MS. 
Os dados foram submetidos às análises de variância e de regressão. A comparação de médias foi realizada usando-se o teste de Tukey a $5 \%$ de probabilidade. Para o fator quantitativo, os modelos foram escolhidos com base na significância dos coeficientes de regressão, utilizando-se o teste $\mathrm{t} a$ $10 \%$ de probabilidade, no coeficiente de determinação ( $R^{2}=$ S.Q. Regressão/S.Q. Tratamento) e no fenômeno biológico. Para execução das análises estatísticas, foram utilizados os programas estatísticos "SAEG 9.0" (2005), desenvolvido pela Universidade Federal de Viçosa, e o "SIGMA PLOT 10.0". Independentemente da interação entre os fatores ser ou não significativa, optou-se pelo seu desdobramento, devido ao interesse em estudo.

\section{Resultados e Discussão}

As médias mensais de radiação solar variaram entre 178 e $301 \mathrm{~W} \mathrm{~m}^{-2}$, sendo seus valores mínimos ocorridos nos meses entre abril e setembro e máximos nos meses entre outubro e março, respectivamente. Os valores médios de temperatura do ar durante o período experimental variaram de 18,8 a $26,1^{\circ} \mathrm{C}$. As temperaturas nunca atingiram valores inferiores à $15^{\circ} \mathrm{C}$, temperatura essa que limita o crescimento e desenvolvimento de gramíneas forrageiras tropicais (Cooper \& Tainton, 1968).

Na Tabela 1 observam-se os valores médios de matéria seca (MS) passível de ser consumida $\left(\mathrm{kg} \mathrm{ha}^{-1}\right)$ em função dos manejos da adubação, períodos de descanso, doses de adubação e épocas climáticas. A produtividade média de MS do capim-xaraés foi de $14.758 \mathrm{~kg} \mathrm{ha}^{-1} \mathrm{ano}^{-1}$. Na literatura, o potencial produtivo dessa gramínea é de 21.000 $\mathrm{kg} \mathrm{ha}^{-1}$ ano $^{-1}$ (Jank et al., 2005), valor esse bem acima do obtido no presente trabalho, pois, para a planta produzir o seu potencial, é necessário que vários fatores responsáveis para o seu crescimento e desenvolvimento estejam em condições ótimas, como clima, adubação, umidade do solo, entre outros. Outra possível explicação seria o fato de a matéria seca ter sido obtida pelo método de simulação de pastejo. Dessa forma, apenas a forragem potencialmente consumível é considerada, e assim seu valor é subestimado ao ser comparado com as produtividades potenciais, que consideram toda a matéria seca (folhas e colmos).

Verifica-se também na Tabela 1 que a produtividade de MS nos diversos tratamentos foi, em geral, maiores na estação primavera/verão em relação à estação outono/inverno. Esse resultado é decorrente dos menores valores de radiação e temperatura na estação outono/inverno (Figura 1). Convém salientar que a temperatura de inverno na região do Município de Governador Valadares é maior que nas regiões onde no passado foram desenvolvidos trabalhos de pesquisa com irrigação de pastagem (Viçosa, MG, Piracicaba, SP, e Triângulo Mineiro). Diante disso, é possível justificar a não-interferência da época climática em alguns tratamentos. Nessas regiões verificou-se expressiva produtividade de MS na estação primavera/verão em relação ao período outono/inverno.

Em média, a produtividade de MS obtida na estação outono/inverno foi de $75 \%$ da obtida na estação primavera/verão. Essa mesma relação foi encontrada por Alencar (2007) avaliando seis

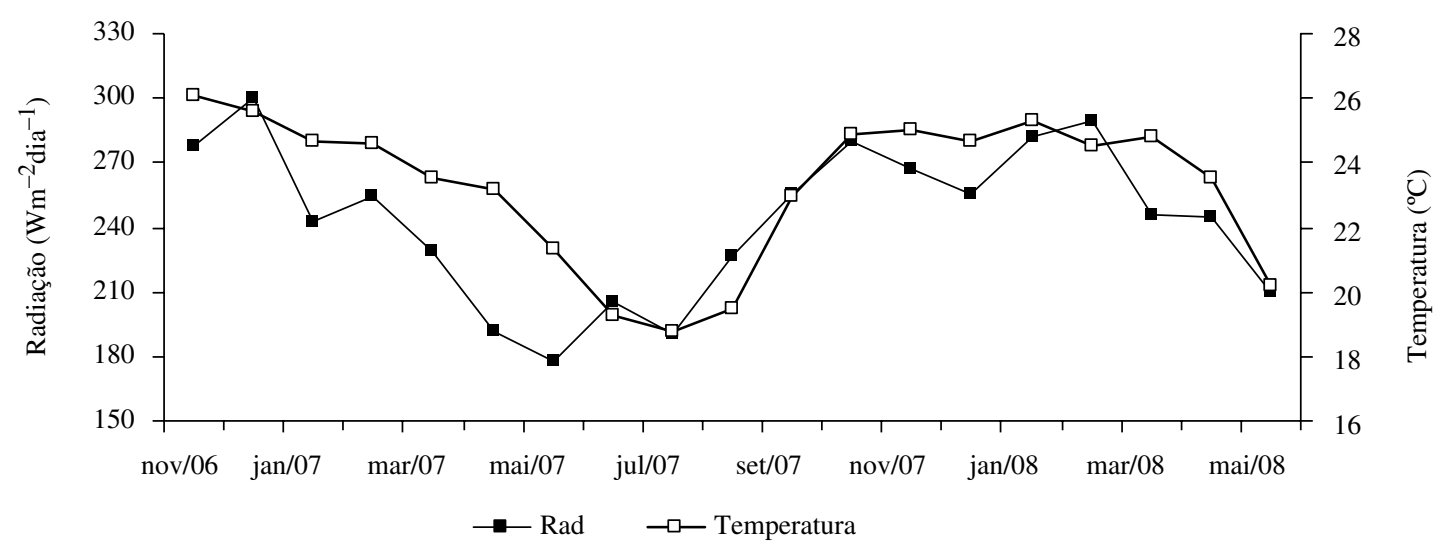

Figura 1. Variação mensal da radiação solar média $\left(\mathrm{W} \mathrm{m}^{-2}\right)$ e da temperatura média $\left({ }^{\circ} \mathrm{C}\right)$, no período de novembro de 2006 a junho de 2008 . 
Tabela 1. Valores médios de matéria seca passível de ser consumida $\left(\mathrm{kg} \mathrm{ha}^{-1}\right)$ nas combinações de períodos de descanso (PD), manejos da adubação (MA), doses de adubação e épocas climáticas.

\begin{tabular}{|c|c|c|c|c|c|c|c|}
\hline \multirow{2}{*}{ PD } & \multirow{2}{*}{ MA } & \multicolumn{2}{|c|}{$0 \%$} & \multicolumn{2}{|c|}{$15 \%$} & \multicolumn{2}{|c|}{$39 \%$} \\
\hline & & Out/Inv & Pri/Ver & Out/Inv & Pri/Ver & Out/Inv & Pri/Ver \\
\hline \multirow[t]{2}{*}{21} & Conv. & $4.408 \mathrm{Ab}$ & $6.757 \mathrm{Aa}$ & $5.358 \mathrm{Ab}$ & 7.378 Aa & $6.157 \mathrm{Ab}$ & $9.710 \mathrm{Aa}$ \\
\hline & Fert. & $4.673 \mathrm{Aa}$ & $5.875 \mathrm{Aa}$ & $5.412 \mathrm{Ab}$ & $7.170 \mathrm{Aa}$ & $6.044 \mathrm{Ab}$ & $8.072 \mathrm{Ba}$ \\
\hline \multirow[t]{2}{*}{28} & Conv. & $5.452 \mathrm{Aa}$ & $5.849 \mathrm{Aa}$ & $5.529 \mathrm{Ab}$ & $7.121 \mathrm{Aa}$ & $5.852 \mathrm{Ab}$ & $8.472 \mathrm{Aa}$ \\
\hline & Fert. & $5.401 \mathrm{Aa}$ & $5.594 \mathrm{Aa}$ & $5.323 \mathrm{Ab}$ & $6.811 \mathrm{Aa}$ & $6.653 \mathrm{Aa}$ & $7.928 \mathrm{Aa}$ \\
\hline \multirow[t]{2}{*}{35} & Conv. & $4.562 \mathrm{Aa}$ & $5.717 \mathrm{Aa}$ & $4.813 \mathrm{Aa}$ & $5.810 \mathrm{Aa}$ & $5.906 \mathrm{Ab}$ & $8.474 \mathrm{Aa}$ \\
\hline & Fert. & $4.667 \mathrm{Aa}$ & $5.370 \mathrm{Aa}$ & $5.223 \mathrm{Aa}$ & $6.201 \mathrm{Aa}$ & $6.875 \mathrm{Ab}$ & $8.871 \mathrm{Aa}$ \\
\hline \multirow[t]{2}{*}{42} & Conv. & $4.143 \mathrm{Ab}$ & $5.823 \mathrm{Aa}$ & $5.327 \mathrm{Aa}$ & $6.642 \mathrm{Aa}$ & $6.308 \mathrm{Ab}$ & $7.976 \mathrm{Aa}$ \\
\hline & Fert. & $5.086 \mathrm{Aa}$ & $6.369 \mathrm{Aa}$ & $5.053 \mathrm{Ab}$ & $6.925 \mathrm{Aa}$ & $5.313 \mathrm{Ab}$ & $8.117 \mathrm{Aa}$ \\
\hline \multirow{2}{*}{ PD } & \multirow{2}{*}{ MA } & \multicolumn{2}{|c|}{$64 \%$} & \multicolumn{2}{|c|}{$83 \%$} & \multicolumn{2}{|c|}{$100 \%$} \\
\hline & & Out/Inv & Pri/Ver & Out/Inv & Pri/Ver & Out/Inv & Pri/Ver \\
\hline \multirow[t]{2}{*}{21} & Conv. & $6.062 \mathrm{Ab}$ & $9.257 \mathrm{Aa}$ & $7.895 \mathrm{Ab}$ & $10.396 \mathrm{Aa}$ & $7.402 \mathrm{Bb}$ & $10.311 \mathrm{Aa}$ \\
\hline & Fert. & $6.431 \mathrm{Ab}$ & $8.325 \mathrm{Aa}$ & $7.981 \mathrm{Ab}$ & $9.310 \mathrm{Aa}$ & $8.762 \mathrm{Ab}$ & $10.101 \mathrm{Aa}$ \\
\hline \multirow[t]{2}{*}{28} & Conv. & $6.917 \mathrm{Ab}$ & $10.133 \mathrm{Aa}$ & $7.026 \mathrm{Ab}$ & $11.181 \mathrm{Aa}$ & $7.714 \mathrm{Ba}$ & $8.435 \mathrm{Ba}$ \\
\hline & Fert. & 7.487 Ab & $9.130 \mathrm{Aa}$ & $8.154 \mathrm{Ab}$ & $10.322 \mathrm{Aa}$ & $9.219 \mathrm{Ab}$ & $10.784 \mathrm{Aa}$ \\
\hline \multirow[t]{2}{*}{35} & Conv. & $7.358 \mathrm{Ab}$ & $8.953 \mathrm{Aa}$ & $7.555 \mathrm{Ab}$ & $10.362 \mathrm{Aa}$ & $6.582 \mathrm{Bb}$ & $8.400 \mathrm{Ba}$ \\
\hline & Fert. & $6.923 \mathrm{Ab}$ & $9.883 \mathrm{Aa}$ & $8.822 \mathrm{Ab}$ & $10.605 \mathrm{Aa}$ & $9.276 \mathrm{Ab}$ & $10.934 \mathrm{Aa}$ \\
\hline \multirow[t]{2}{*}{42} & Conv. & $6.464 \mathrm{Ab}$ & $8.047 \mathrm{Ba}$ & $6.354 \mathrm{Ab}$ & $9.333 \mathrm{Aa}$ & $7.737 \mathrm{Aa}$ & $8.549 \mathrm{Aa}$ \\
\hline & Fert. & $6.470 \mathrm{Ab}$ & $9.674 \mathrm{Aa}$ & $7.329 \mathrm{Ab}$ & $9.332 \mathrm{Aa}$ & $7.169 \mathrm{Ab}$ & $8.945 \mathrm{Aa}$ \\
\hline
\end{tabular}

Médias seguidas de letras maiúsculas diferenciam os manejos de adubação, dentro de cada período de descanso, e seguidas de letras minúsculas diferenciam as estações do ano, dentro de cada nível de adubação, de acordo com o teste de Tukey $(p<0,05)$.

forrageiras, dentre elas o capim-xaraés, na mesma área experimental do presente trabalho. Vítor $e t$ al. (2009), avaliando o capim-elefante irrigado em Coronel Pacheco, MG, região essa que apresenta maior latitude que o local do presente trabalho, obteve relação inverno/verão em torno de $30 \%$.

Verificou-se que a fertirrigação proporcionou maior produtividade de MS do capim-xaraés em relação à adubação convencional apenas nas maiores doses de adubação; nos demais tratamentos, verificou-se semelhança entre os manejos de adubação (Tabela 1). Mesmo não havendo diferença entre todos os tratamentos, recomenda-se a utilização da fertirrigação, devido aos seguintes benefícios: redução dos custos de aplicação; evita-se a movimentação de máquinas na lavoura para a distribuição do fertilizante; maior parcelamento dos fertilizantes; possibilidade de incorporar os nutrientes móveis no perfil do solo; entre outros.

Quanto ao efeito proporcionado pelas doses de adubação na produtividade de MS, verificou-se na Figura 2, resposta linear positiva para o tratamento fertirrigado e estação outono/inverno e quadrática para os demais tratamentos. Para o tratamento fertirrigado e estação primavera/verão, a dose de adubação que maximiza a produtividade de MS estimada pela equação foi de $125 \%\left(875 \mathrm{~kg} \mathrm{ha}^{-1} \mathrm{ano}^{-1}\right.$ de $\mathrm{N}$ e $700 \mathrm{~kg} \mathrm{ha}^{-1}$ ano $^{-1}$ de $\mathrm{K}_{2} \mathrm{O}$ ). No tratamento de manejo de adubação convencional, os máximos estimados obtidos pelas equações foram de $143 \%$ (1.004 kg ha ${ }^{-1}$ ano $^{-1}$ de N e $803 \mathrm{~kg} \mathrm{ha}^{-1} \mathrm{ano}^{-1}$ de $\mathrm{K}_{2} \mathrm{O}$ ) e $79 \%$ (554 kg ha ${ }^{-1} \mathrm{ano}^{-1}$ de N e $443 \mathrm{~kg} \mathrm{ha}^{-1}$ $\mathrm{ano}^{-1}$ de $\mathrm{K}_{2} \mathrm{O}$ ) para as estações outono/inverno e primavera/verão, respectivamente.

Resultados diferentes foram encontrados por Alencar (2007). O autor aplicando 100, 300, $500 \mathrm{e}$ $700 \mathrm{~kg} \mathrm{ha}^{-1} \mathrm{ano}^{-1}$ de $\mathrm{N}$ em seis capins, dentre eles o Xaraés, na mesma área experimental do presente trabalho, não verificou resposta na produtividade de MS. Essa diferença possivelmente pode ser justificada por dois fatores. Um deles seria devido a degradação do solo causada pelo pastejo, pois, enquanto no presente trabalho o experimento foi realizado por um ano, Alencar (2007) avaliou os capins por dois anos. Dessa forma a intensidade de pisoteio animal foi maior acarretando maiores 


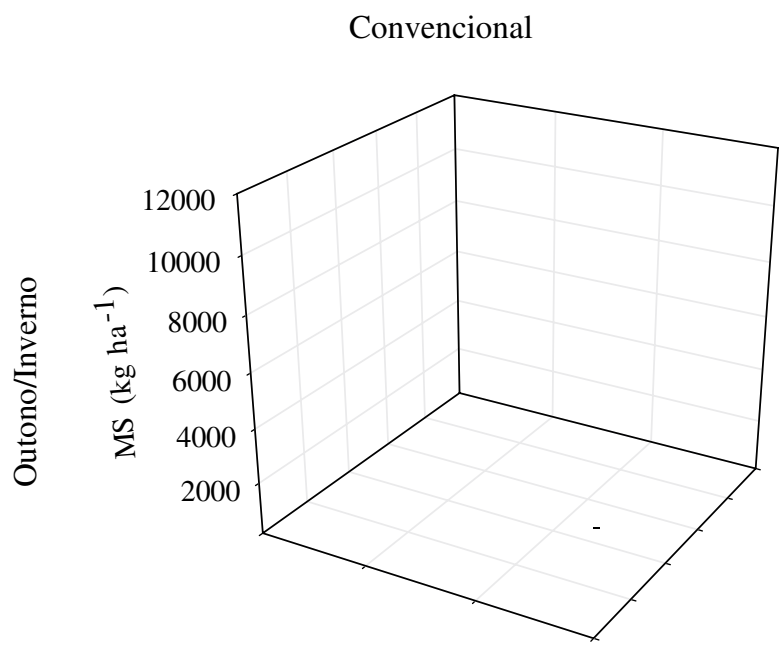

$\mathrm{MS}=4.644,02+42,2060^{* *} \mathrm{DA}-0,1472^{*} \mathrm{DA}^{2}$

$\mathrm{p}<0,0001 \quad \mathrm{R}^{2}=0,8378$

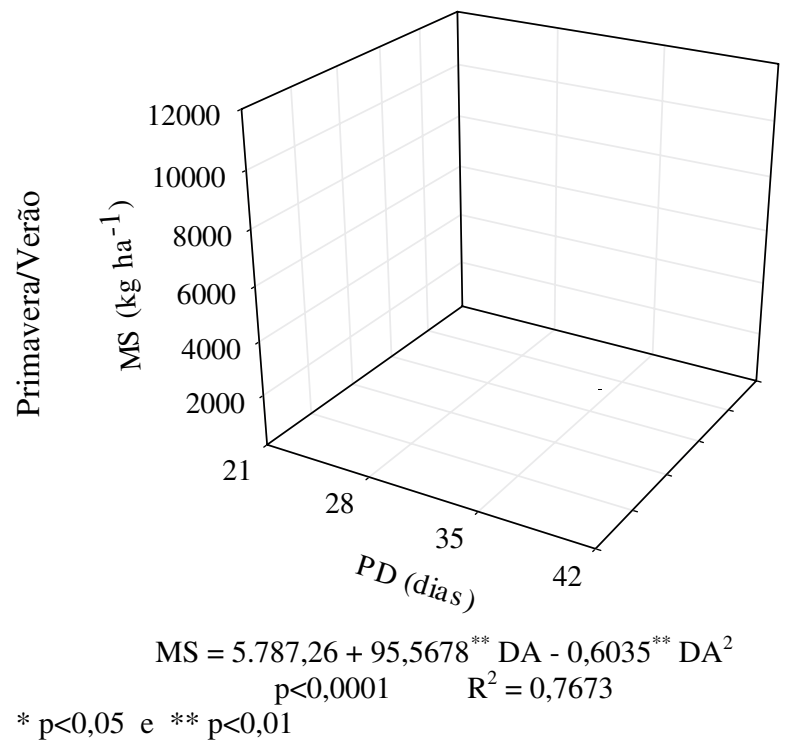

Fertirrigação

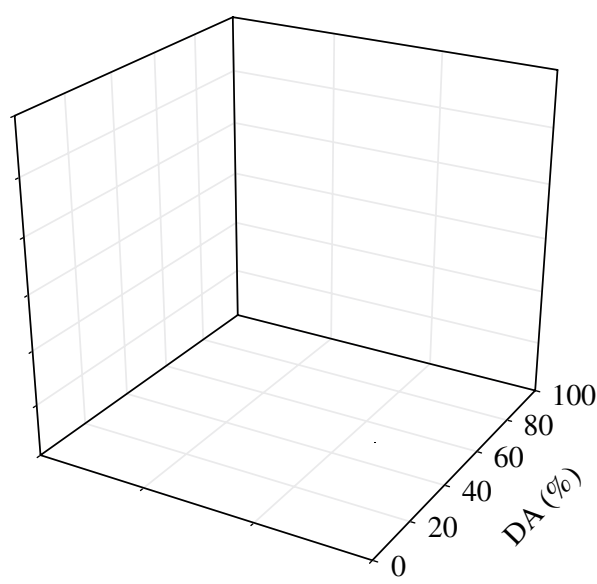

$$
\begin{gathered}
\mathrm{MS}=-1.096,64+422,1308^{* *} \mathrm{PD}+\ldots \\
\ldots+37,4149^{* *} \mathrm{DA}-7,0445^{* *} \mathrm{PD}^{2} \\
\mathrm{p}<0,0001 \quad \mathrm{R}^{2}=0,9216
\end{gathered}
$$

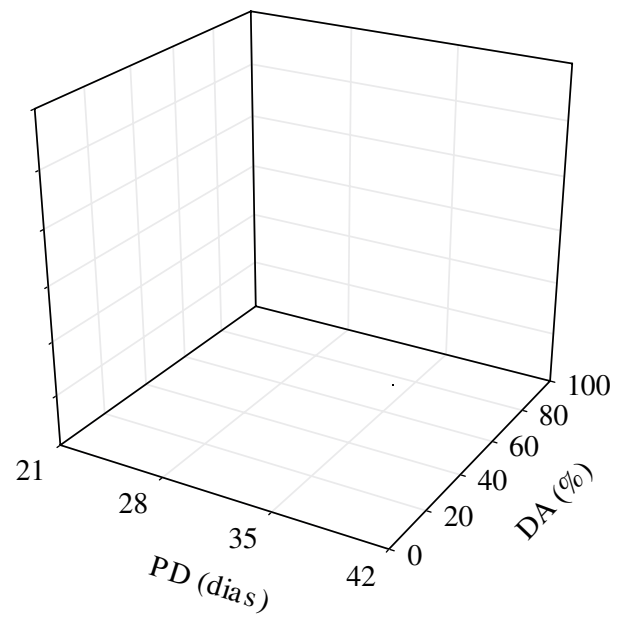

$$
\begin{aligned}
& \mathrm{MS}=5.781,46+73,6754^{* *} \mathrm{DA}-0,2949^{*} \mathrm{DA}^{2} \\
& \mathrm{p}<0,0001 \quad \mathrm{R}^{2}=0,9003
\end{aligned}
$$

Figura 2. Estimativa da produtividade de matéria seca passível de ser consumida (MS) do capim-xaraés submetido a diferentes manejos de adubação e épocas climáticas, em função dos períodos de descanso (PD) e doses de adubação (DA).

problemas como selamento superficial e redução da taxa de infiltração de água. Segundo Silva et al. (1997) o solo impõe outras limitações no crescimento de plantas, dependendo da sua capacidade de suprir nutrientes, água e oxigênio em quantidades suficientes para atender ao potencial de crescimento determinado pelo clima. Outra possível explicação seria o fato das doses nitrogenadas no presente trabalho serem acompanhadas de doses potássicas na adubação. Alencar (2007) aplicou $150 \mathrm{~kg} \mathrm{ha}^{-1}$ $\mathrm{ano}^{-1}$ de $\mathrm{K}_{2} \mathrm{O}$ para todos os tratamentos, já no presente trabalho, obedeceu-se uma relação de $1 \mathrm{~N}$ : $0,8 \mathrm{~K}_{2} \mathrm{O}$, então no tratamento que recebeu $700 \mathrm{~kg}$ $\mathrm{ha}^{-1} \mathrm{ano}^{-1} \mathrm{de} \mathrm{N}$, a dose potássica foi de $560 \mathrm{~kg} \mathrm{ha}^{-1}$ $\mathrm{ano}^{-1}$. Primavesi et al. (2006) relata que a adubação potássica aumenta a eficiência de uso do N. Costa 
et al. (2008), avaliando o efeito da adubação nitrogenada e potássica na concentração de nutrientes do capim-xaraés em Santo Antônio de Goiás, GO, verificaram que a adubação potássica promoveu aumento de $44,7 \%$ na concentração de $\mathrm{N}$ na folha, em relação à não-aplicação desse nutriente. Esses resultados evidenciam a importância da adubação potássica para essa cultivar, principalmente em situações de elevados níveis de adubação nitrogenada.

$\mathrm{Na}$ literatura, encontram-se trabalhos com resultados semelhantes ao presente trabalho. Martuscello et al. (2005) observaram que o aumento da dose nitrogenada proporcionou aumento linear na produtividade de MS do capim-xaraés. Os autores trabalharam com doses nitrogenadas de 0 , 40,80 e $120 \mathrm{mg} \mathrm{dm}^{-3}$ em experimento montado no Município de Viçosa, MG. Fagundes et al. (2005), trabalhando com o capim-braquiária no Município de Viçosa, MG, com sistema de pastejo e aplicando $75,150,225$ e $300 \mathrm{~kg} \mathrm{ha}^{-1}$ ano $^{-1}$ de N, verificaram que a produtividade de MS respondeu com o aumento da dose de $\mathrm{N}$, independentemente da época climática. Nas estações verão, outono e inverno, o comportamento foi linear positivo, enquanto na estação primavera o comportamento foi quadrático.

No tratamento fertirrigado e estação outono/ inverno, os períodos de descanso proporcionaram efeito quadrático na produtividade de MS (Figura 2), cujo máximo estimado obtido pela equação foi de aproximadamente 30 dias. Nos demais tratamentos, não foram verificados efeitos dos períodos de descanso. Costa et al. (2007) avaliando o capim-marandu, da mesma espécie do capim avaliado no presente trabalho, no município de Porto Velho, $\mathrm{RO}$, verificaram que o aumento do período de descanso resultou em maiores rendimentos de forragem, porém os mesmos autores concluíram que o período de descanso mais adequado ficou entre 28 e 42 dias, ou seja, no intervalo avaliado no presente trabalho.

\section{Conclusões}

A estação outono/inverno proporciona menor produtividade de matéria seca; porém, em média, a produtividade na estação outono/inverno é de $75 \%$ daquela obtida na estação primavera/verão. Os manejos de adubação não influenciam os valores de produtividade de MS, porém o aumento da dose de adubação proporciona efeito linear positivo no capim-xaraés fertirrigado na estação outono/inverno e quadrático nos demais tratamentos. No tratamento fertirrigado e estação outono/inverno, recomenda-se o período de descanso de 30 dias.

\section{Referências Bibliográficas}

Alencar, C.A.B.

2007 Produção de seis gramíneas forrageiras tropicais submetidas a diferentes lâminas de água e doses de nitrogênio, na região Leste de Minas Gerais. 2007. 121p. Tese (Doutorado em Engenharia Agrícola)-Universidade Federal de Viçosa.

Andrade, A.C.; Fonseca, D.M.; Gomide, J.A.; Alvarez V., V.H.; Martins, C.E. \& Souza, D.P.H.

2000 Produtividade e valor nutritivo do capim-elefante cv. Napier sob doses crescentes de nitrogênio e potássio. Revista Brasileira de Zootecnia, 29 (6): 1589-1595.

Aroeira, L.J.M.; Lopes, F.C.F.; Deresz, F.; Verneque, R.S.; Dayrell, M.S.; Matos, L.L.; Maldonado Vasquez, H. \& Vittori, A. 1999 Pasture availability and dry matter intake of lactating crossbred cows grazing elephant grass (Pennisetum purpureum, Schum). Animal Feed Science and Technology, 78 (2): 313-324.

CFSEMG, Comissão De Fertilidade Do Solo Do Estado De Minas Gerais.

1999 Recomendações para o uso de corretivos e fertilizantes em Minas Gerais: $5^{\mathrm{a}}$ aproximação. 20.ed. Viçosa: Editora UFV, 359p.

Cooper, J.P. \& Tainton, N.M.

1968 Light and temperature requirements for the growth of tropical and temperate grasses. Review article. Herbage Abstracts, 38 (3): 167-176.
Costa, K.A.; Oliveira, I.P.; Faquin, V.; Figueiredo, F.C.; Rodrigues,

C.R. \& Nascimento, P.P.

2008 Adubação nitrogenada e potássica na concentração de nutrientes do capim-xaraés. Ciência Animal Brasileira, 9 (1): 86-92.

Costa, N.L.; Paulino, V.T.; Townsend, C.R.; Magalhães, J.A. \& Oliveira, J.R.C.

2007 Desempenho agronômico de genótipos de Brachiaria brizantha em diferentes idades de corte em Porto Velho, Rondônia, Brasil. Revista Electrónica de Veterinária, 8 (8): $1-5$.

Cunha, F.F.; Soares, A.A.; Pereira, O.G.; Lambertucci, D.M. \& Abreu, F.V.S.

2007 Características morfogênicas e perfilhamento do Panicum maximum Jacq. cv. Tanzânia irrigado. Ciência e Agrotecnologia, 31 (3): 628-635.

Fagundes, J.L.; Fonseca, D.M.; Gomide, J.A.; Nascimento Jr., D.; Vitor, C.M.T.; Morais, R.V.; Mistura, C.; Reis, G.C. \& Martuscello, J.A.

2005 Acúmulo de forragem em pastos de Brachiaria decumbens adubados com nitrogênio. Pesquisa Agropecuária Brasileira, 40 (4): 397-403.

Hanks, R.J.; Keller, J.; Rasmussen, V.P. \& Wilson, G.D. 1976 Line source sprinkler for continuous variable irrigationcrop production studies. Soil Science Society of America Journal, 40 (3): 426-429. 
IBGE, Instituto Brasileiro de Geografia e Estatística.

$2009<$ http://www.ibge.gov.br> 14 jun. 2009.

Jank, L.; Valle, C.B.; Karia, C.T.; Pereira, A.V.; Batista, L.A.R. \& Resende, R.M.S.

2005 Opções de novas cultivares de gramíneas e leguminosas forrageiras tropicais para Minas Gerais. Informe Agropecuário, 28 (226): 26-35.

Martuscello, J.A.; Fonseca, D.M.; Nascimento Jr., D.; Santos, P.M.; Ribeiro Jr., J.I.; Cunha, D.N.F.V. \& Moreira, L.M.

2005 Características morfogênicas e estruturais do capim-xaraés submetido à adubação nitrogenada e desfolhação.

Revista Brasileira de Zootecnia, 34 (5): 1475-1482.

Primavesi, A.C.; Primavesi, O.; Corrêa, L.A.; Silva, A.G. \& Cantarella, $\mathrm{H}$.

2006 Nutrientes na fitomassa de capim-marandu em função de fontes e doses de nitrogênio. Ciência e Agrotecnologia, 30 (3): 562-568.
Richards, L.A.

1949 Methods of measuring soil moisture tension. Soil Science of American Journal, 68 (1): 95-112.

Silva, A.P.; Tormena, C.A. \& Mazza, J.A.

1997 Manejo físico de solos sob pastagem. In: Simpósio sobre Manejo da Pastagem, 14, Piracicaba, SP. Anais... Piracicaba, SP, pp. 25-37.

Vítor, C.M.T.; Fonseca, D.M.; Cóser, A.C.; Martins, C.E.; Nascimento Jr., D. \& Ribeiro Jr., J.I.

2009 Produção de matéria seca e valor nutritivo de pastagem de capim-elefante sob irrigação e adubação nitrogenada. Revista Brasileira de Zootecnia, 38 (3): 435-442.

\section{Anexo}

\section{Análise de variância}

\begin{tabular}{lcc}
\hline Fonte de Variação & Grau de Liberdade & Quadrado Médio \\
\hline EC & 1 & $3,46 \mathrm{E}+08^{* *}$ \\
MA & 1 & $6,43 \mathrm{E}+06 *$ \\
EC x MA & 1 & $3,60 \mathrm{E}+06^{\mathrm{NS}}$ \\
Resíduo (a) & 12 & $1,22 \mathrm{E}+06$ \\
PD & 3 & $6,05 \mathrm{E}+06 * *$ \\
PD x EC & 3 & $9,47 \mathrm{E}+05^{\mathrm{NS}}$ \\
PD x MA & 3 & $4,06 \mathrm{E}+06 * *$ \\
PD x EC x MA & 3 & $3,07 \mathrm{E}+06 *$ \\
Resíduo (b) & 36 & $8,36 \mathrm{E}+05$ \\
DA & 5 & $1,34 \mathrm{E}+08^{* *}$ \\
DA x EC & 5 & $5,20 \mathrm{E}+06 * *$ \\
DA x MA & 5 & $4,05 \mathrm{E}+06 * *$ \\
DA x PD & 15 & $1,91 \mathrm{E}+06 * *$ \\
DA x EC x MA & 5 & $1,12 \mathrm{E}+06 *$ \\
DA x EC x PD & 15 & $7,48 \mathrm{E}+05 *$ \\
DA x MA x PD & 15 & $1,45 \mathrm{E}+06 * *$ \\
DA x EC x MA x PD & 15 & $6,37 \mathrm{E}+05^{*}$ \\
Resíduo (c) & 240 & $3,66 \mathrm{E}+05$ \\
\hline Total & 383 & $3,46 \mathrm{E}+06$ \\
\hline CV (\%) Parcela & & 14,97 \\
CV (\%) Subparcela & & 12,39 \\
CV (\%) Subsubparcela & & 8,20 \\
\hline
\end{tabular}

$\mathrm{EC}=$ épocas climáticas; $\mathrm{MA}=$ manejos da adubação; $\mathrm{PD}=$ períodos de descanso e DA $=$ doses de adubação. ** $\mathrm{F}$ significativo a $1 \%$ de probabilidade; * $\mathrm{F}$ significativo a $5 \%$ de probabilidade; $\mathrm{e}^{\mathrm{NS}} \mathrm{F}$ não-significativo a $5 \%$ de probabilidade. 